\author{
P. P. Roeleveld \\ D. Guijt \\ E. J. Kuijper \\ M. G. Hazekamp \\ R. B. P. de Wilde \\ E. de Jonge
}

\section{Ventilator-associated pneumonia in children after cardiac surgery in The Netherlands}

Received: 29 September 2010 Accepted: 14 July 2011

Published online: 30 August 2011

(C) The Author(s) 2011. This article is published with open access at Springerlink.com
P. P. Roeleveld $(\bowtie) \cdot$ D. Guijt R. B. P. de Wilde · E. de Jonge Pediatric Intensive Care Unit, Leiden University Medical Center, Albinusdreef 2, PO Box 9600, 2300 RC Leiden, The Netherlands e-mail: p.p.roeleveld@lumc.nl Tel.: +31-71-5261677

Fax: +31-71-5266966

\section{E. J. Kuijper}

Department of Microbiology,

Leiden University Medical Center, Leiden, The Netherlands

\section{G. Hazekamp}

Department of Cardiothoracic Surgery, Leiden University Medical Center,

Leiden, The Netherlands

\begin{abstract}
Purpose: We conducted a retrospective cohort study in an academic tertiary care center to characterize ventilator-associated pneumonia (VAP) in pediatric patients after cardiac surgery in The Netherlands. Methods: All patients following cardiac surgery and mechanically ventilated for $\geq 24 \mathrm{~h}$ were included. The primary outcome was development of VAP. Secondary outcomes were duration of mechanical ventilation and length of ICU stay. Results: A total of 125 patients were enrolled. Their mean age was 16.5 months. The rate of VAP was 17.1/1,000 mechanical ventilation
\end{abstract}

days. Frequently found organisms were Haemophilus influenzae, Moraxella catarrhalis, Staphylococcus aureus and Pseudomonas aeruginosa. Patients with VAP had longer duration of ventilation and longer ICU stay. Risk factors associated with the development of VAP were a PRISM III score of $\geq 10$ and transfusion of fresh frozen plasma. Conclusion: The mean VAP rate in this population is higher than that reported in general pediatric ICU populations. Children with VAP had a prolonged need for mechanical ventilation and a longer ICU stay.

Keywords Ventilator-associated pneumonia - Cardiac surgery . Children $\cdot$ Nosocomial $\cdot$ PICU

\section{Introduction}

Ventilator-associated pneumonia (VAP) is defined as nosocomial pneumonia developing $48 \mathrm{~h}$ or more after initiation of mechanical ventilation. It accounts for $20 \%$ of all nosocomial infections among patients in pediatric intensive care units (PICU) and has a rate of 2.9-21.6/ 1,000 ventilator days [1-3]. Epidemiology and outcomes of VAP have been extensively researched in adults. Independent risk factors for VAP include duration of mechanical ventilation, severity of illness, patient age, supine head position, previous antibiotic treatment, reintubation, transport out of the ICU, and the use of histamine-2 blockers [4]. VAP is more common among adults who have undergone major heart surgery than in the general population of ICU patients [5].

Fewer data exist for pediatric patients, and most of these data come from studies of the general PICU population. Possible risk factors that have been identified include the presence of a genetic syndrome, reintubation, prolonged duration of mechanical ventilation, prolonged use of a central venous catheter, enteral feeding and transport out of the PICU [3, 6-8]. VAP in PICU patients is associated with adverse outcomes including greater length of stay, longer duration of mechanical ventilation and higher mortality $[3,6,8,9]$.

There has been no previous research to characterize VAP among PICU patients in The Netherlands, and only 
a few previous international studies have looked specifically at VAP among PICU patients following cardiac surgery $[3,9,10]$. The objective of this study was to describe the rates, potential risk factors, and outcomes of VAP among pediatric patients following cardiac surgery.

\section{Materials and methods}

\section{Setting}

The study was conducted in the Leiden University Medical Center (LUMC), an academic tertiary care center. The PICU is a combined medical surgical ICU that has eight beds, and admits 400 patients per year.

\section{Patients}

All patients admitted to the PICU after cardiothoracic surgery in 2008 and mechanically ventilated for $24 \mathrm{~h}$ or more were retrospectively identified and included in the study.

\section{Standard practice}

Patients were intubated with a microcuff tube (high volume, low pressure) in the operating room. Patients received $0.5 \mathrm{mg} / \mathrm{kg}$ dexamethasone prior to going on cardiopulmonary bypass. On arrival in the PICU, all patients were sedated with morphine and midazolam. Patients did not receive standard neuromuscular blockade postoperatively, but only the first night if their chest remained open. All intubated patients had routine daily chest radiography and were placed in semi-recumbent position. Sucralfate was given for gastric ulcer protection while nil by mouth. Pantoprazole was given if corticosteroids were continued. Oral hygiene was maintained by cleaning with wet dental swabs three or four times daily.

Perioperative antibiotic prophylaxis consisted of $24 \mathrm{~h}$ of cefazoline or flucloxacillin if chest closure was delayed. Empirical antibiotic treatment consisted of vancomycin and ceftazidime for infants $<2$ months of age, and cefuroxim and gentamicin for children $>2$ months of age. When there was a suspicion of infection, blood and urine were taken for culture. Endotracheal secretions were obtained using standard tracheal suctioning and analyzed using semiquantitative techniques and microscopic qualitative techniques. No bronchoalveolar lavage was performed or blind telescopic catheters used.
Data collection and study type

Information was retrieved from a prospectively collected patient data management system (PDMS; iMDsoft, Needham, MA) including demographic data, cardiac diagnosis, duration of cardiopulmonary bypass, aortic cross-clamp time, and Pediatric Risk of Mortality (PRISM) III score upon admission. The presence of a central line, an endotracheal tube, a nasogastric/jejunal tube and their characteristics were recorded, as well as: medication use, use of blood products, procedures (i.e. transport out of the PICU, reoperation, delayed chest closure in PICU, reintubation), duration of ventilation and PICU length of stay. A more detailed chart review was performed on all patients in whom there was a suspicion of infection, as retrospectively defined by the fact that endotracheal aspirates had been taken. Clinical indicators of VAP (minimum and maximum temperatures, presence of purulent sputum, changes in ventilator demands), microbiology and laboratory results, and chest radiographs were examined. Our institutional review board waived the need for formal approval.

\section{Definitions}

Nosocomial infection was defined as an infection not present or incubating at the time of PICU admission with an onset at least $48 \mathrm{~h}$ after admission. VAP was defined as nosocomial pneumonia in patients receiving mechanical ventilation developing $48 \mathrm{~h}$ or more after initiation of mechanical ventilation. Primary outcome was diagnosis of pneumonia based on the Center of Disease Control and National Nosocomial Infections Surveillance (CDC/ NNIS) criteria (Fig. 1) [11].

Worsening gas exchange was defined by an increase in fraction of inspired oxygen $\left(\mathrm{FiO}_{2}\right)$, peak inspiratory pressure (Pip), and/or positive end expiratory pressure (Peep). $\mathrm{PaO}_{2} / \mathrm{FiO}_{2}$ ratios and alveolar-arteriolar oxygen (A-a) gradients were calculated for patients without cardiac shunting. The complexity of cardiac surgery was scored using the risk-adjusted congenital heart surgery (RACHS-1) system, which ranges from 1 to 6, with higher scores correlating with more complex surgery and higher in-hospital mortality [12].

\section{Data analysis}

Data were analyzed using SPSS version 16.0. Distribution of continuous variables was evaluated using the Kolmogorov-Smirnov test. Depending on the distribution a Student's $t$ test or Mann-Whitney $U$ test was performed. Categorical variables were compared using the chisquared test, and if expected frequencies less than five were found in contingency tables Fisher's exact test was 
Fig. 1 Age-specific criteria for the diagnosis of pneumonia [11] (reproduced with permission from the publisher)

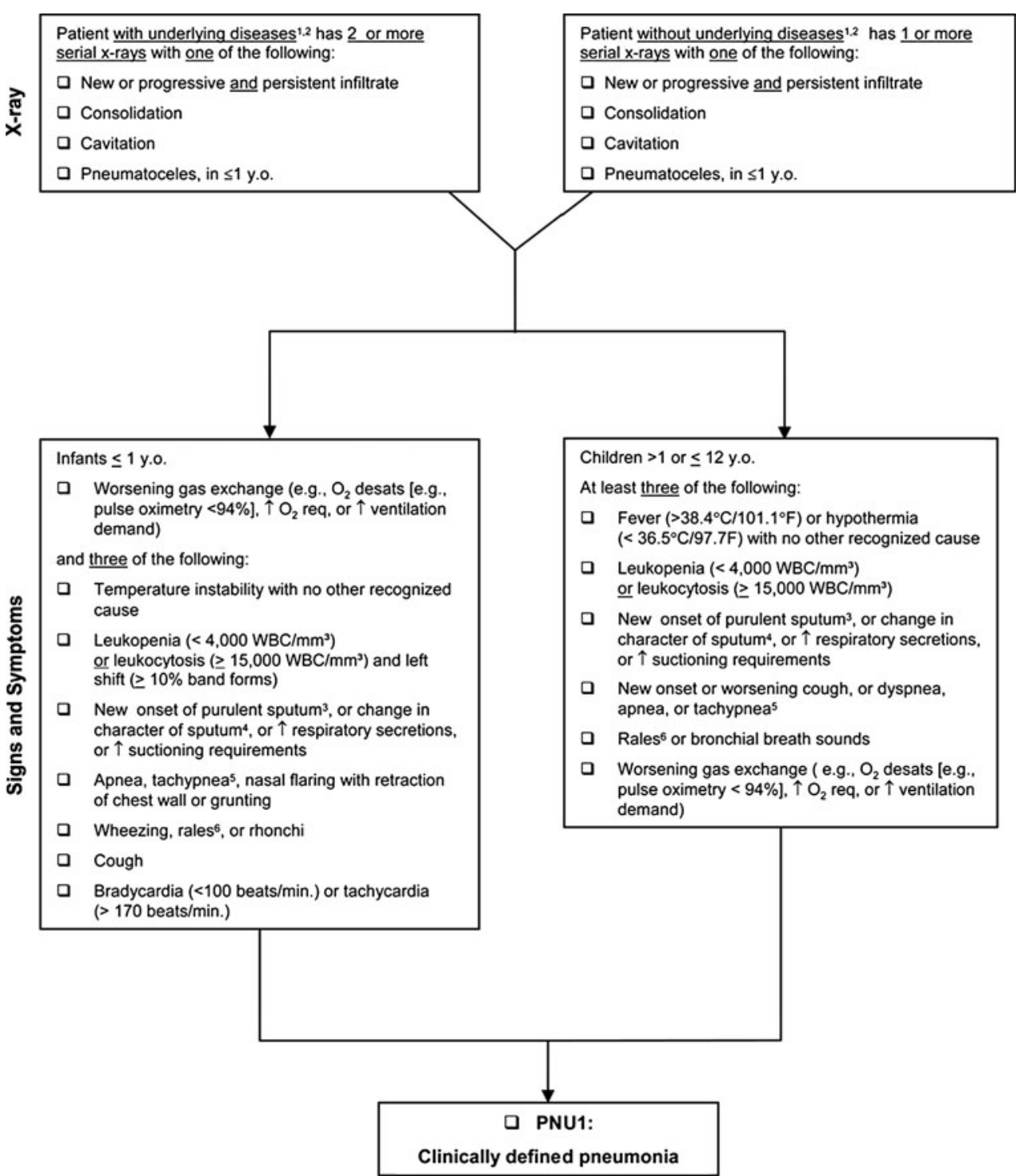

used. All statistical tests were two-tailed. All significant variables $(p<0.1)$ in univariate analysis were further analyzed using logistic regression analysis.

All patients initially suspected of having an infection were divided into four groups: (1) VAP, (2) pulmonary infection that did not fully meet CDC/NNIS criteria for VAP, (3) nonpulmonary infection, and (4) no infection.

\section{Results}

In 2008, a total of 403 patients were admitted to the PICU. Of these patients, 198 had undergone cardiac surgery of whom 125 had been ventilated for $>24 \mathrm{~h}$ and were included in the study. The patients had a median age of 4.2 months, $54.4 \%$ were male, and $82.3 \%$ had undergone an operation on cardiopulmonary bypass. Baseline characteristics are summarized in Table 1 . Of the 125 patients included for review, 91 (73\%) were clinically suspected of having an infection by the treating intensivist (fever, raised inflammatory markers, worsening gas exchange, or purulent sputum) and blood and/or sputum were taken for culture. In 72 of those suspected of having an infection, empirical antibiotics were started. Which infections these patients actually developed were also retrospectively reviewed. The distribution of the study population is illustrated schematically in Fig. 2.

Pulmonary infections were the most common nosocomial infections. Of the 125 patients, 11 (8.8\%) retrospectively qualified for the diagnosis of VAP, 7 (5.6\%) were identified as having a pulmonary infection that did not meet the criteria for VAP (they had been intubated for $<48 \mathrm{~h}$ at the time of diagnosis), 12 (9.6\%) 
Table 1 Study population characteristics $(n=125)$

\begin{tabular}{|c|c|}
\hline Characteristics & Value \\
\hline \multicolumn{2}{|l|}{ Demographics } \\
\hline Male, $n(\%)$ & $68(54.4)$ \\
\hline Age (months), median (interquartile range) & $4.16(0.52-24.77)$ \\
\hline Weight $(\mathrm{kg})$, median (interquartile range) & $4.7(3.50-11.00)$ \\
\hline PRISM III score (mean \pm SD) & $8.2 \pm 4.5$ \\
\hline PRISM III score $\geq 10, n(\%)$ & $38(30.4)$ \\
\hline A genetic syndrome, $n(\%)$ & $18(14.4)$ \\
\hline Previous operation, $n(\%)$ & $44(35.2)$ \\
\hline Prior antibiotics, $n(\%)$ & $4(3.2)$ \\
\hline \multicolumn{2}{|l|}{ Operation } \\
\hline Use of cardiopulmonary bypass, $n(\%)$ & $102(82.3)$ \\
\hline $\begin{array}{l}\text { Duration of cardiopulmonary bypass (min), } \\
\text { mean } \pm \text { SD }\end{array}$ & $118 \pm 82.1$ \\
\hline $\begin{array}{l}\text { Aortic cross-clamp time (min), median } \\
\text { (interquartile range) }\end{array}$ & $56(0-94)$ \\
\hline RACHS score (mean $\pm \mathrm{SD}$ ) & $2.87 \pm 0.95$ \\
\hline \multicolumn{2}{|l|}{ Procedures, $n(\%)$} \\
\hline Delayed closure of sternum & $21(16.8)$ \\
\hline Re-operation & 27 (21.6) \\
\hline Transport out of the PICU & 17 (13.6) \\
\hline Transfusion & $114(91.2)$ \\
\hline Total parenteral nutrition & $10(7.9)$ \\
\hline Cuffed endotracheal tube & $116(92.8)$ \\
\hline \multicolumn{2}{|l|}{ Outcome } \\
\hline $\begin{array}{l}\text { Duration of ventilation }(\mathrm{h}) \\
\text { median (interquartile range) }\end{array}$ & $93(36.50-145.50)$ \\
\hline $\begin{array}{l}\text { PICU length of stay (days), } \\
\text { median (interquartile range) }\end{array}$ & $8(5.0-12.0)$ \\
\hline Death, $n(\%)$ & $3(2.4)$ \\
\hline
\end{tabular}

Number $(\%)$ values were normally distributed, median (interquartile range) values were not normally distributed

developed a central line-related bacteremia (caused by coagulase-negative staphylococcus in 9 of the 12 patients, S. aureus in 1 patient and Enterococcus and S. aureus in 2 patients). None of the patients with VAP had positive blood cultures. Of the 125 patients. 12 (9.6\%) developed another infection (including wound infection, urinary tract infection, and gastrointestinal infection), and 4 $(3.2 \%)$ were receiving antibiotic therapy at the time of admission. None of these patients developed VAP. In 30 patients $(24 \%)$ no infection developed and antibiotics had been stopped within $48 \mathrm{~h}$.

The mean VAP rate was 17.1 per 1,000 ventilation days (11 patients and 644.17 total ventilation days). The mean time between intubation and diagnosis of VAP was 7.4 days. The most common organism cultured in patients with VAP was Haemophilus influenzae, followed by Moraxella catarrhalis, S. aureus and Pseudomonas aeruginosa (Table 2).

The results of the univariate analysis comparing patients with and without VAP are summarized in Table 3. Patients with VAP were more likely to have had an admission PRISM score of $\geq 10(p=0.033)$, and were significantly more likely to have received one or more transfusions of fresh frozen plasma $(p=0.050)$. Aortic cross-clamp time was longer in the patients with VAP (mean 90.9 vs. $57.0 \mathrm{~min}$ ), approaching statistical significance $(p=0.056)$.

All factors with $p \leq 0.1$ in the univariate analysis were entered into a logistic regression analysis (Table 4). Only a PRISM score $\geq 10$ was associated with the development of VAP, with an odds ratio of 4.39 (95\% CI 1.06-18.04).

VAP was associated with a longer duration of ventilation and longer length of stay in the PICU. Mean duration of ventilation was $181 \mathrm{~h}(\mathrm{SD} \pm 94 \mathrm{~h})$ in patients with VAP, and $118 \mathrm{~h}(\mathrm{SD} \pm 138 \mathrm{~h})$ in patients without $\operatorname{VAP}(p=0.002)$. Mean length of stay in the PICU was 13.0 days (SD \pm 6.8 days) for patients with VAP and 10.4 days (SD \pm 10.2 days) for patients without VAP $(p=0.009)$. There were no deaths among the patients with VAP.

\section{Discussion}

We performed a retrospective cohort study of VAP in PICU patients following cardiac surgery. Only a few previous studies have looked at VAP in this specific patient population $[3,9,10]$. This is the first study to characterize VAP in a PICU population in The Netherlands. Of the 125 patients included in the study, 11 (8.8\%) developed VAP giving a rate of 17.1 episodes of VAP per 1,000 ventilator days. Fischer et al. [9] found a comparable rate of $9.6 \%$. Tang et al. [3] reported a higher incidence of $13 \%$ and 21.6 episodes of VAP per 1,000 ventilator days, despite a 3-day prophylaxis with cefazoline and gentamicin compared to our 24-h prophylaxis with cefazoline. Our use of cuffed tubes might be an explanation for the lower VAP incidence. Even though modern microcuffed tubes do not necessarily provide an isolated airway and tracheal soiling can probably still occur, in adults the use of cuffed endotracheal tubes has been shown to reduce the incidence of VAP $[13,14]$.

Tan et al. [10] reported an even higher incidence of $21.5 \%$ for acquired nosocomial pneumonia in children after cardiac surgery. However, this incidence probably does not reflect the incidence of true VAP, as they did not comment on the temporal relationship with mechanical ventilation. Rates reported in general PICU populations are generally lower than those found in our study: between 2.9 and 11.6 per 1,000 ventilator days $[2,6]$. Higher VAP rates for surgical and trauma ICUs versus medical ICUs were reported in the 2004 NNIS survey in both adult and pediatric studies [4, 7, 8, 15].

There is no gold standard for the diagnosis of VAP in pediatric patients. The diagnostic criteria of VAP remain contentious. We adhered to the criteria proposed by 
Fig. 2 Distribution of study population

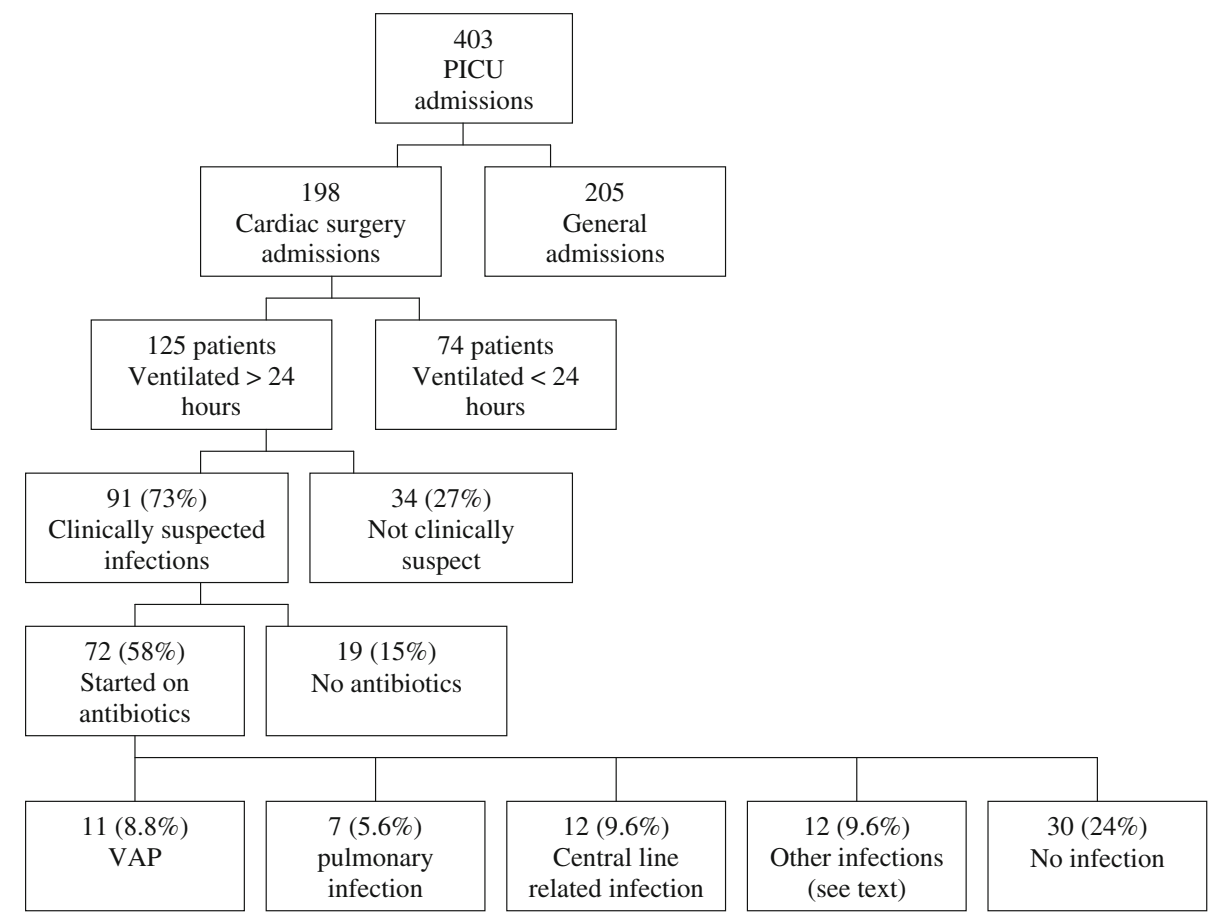

Table 2 Results of the tracheal secretion cultures in the 11 patients with VAP

\begin{tabular}{ll}
\hline Organism & No. (\%) of patients \\
\hline Haemophilus influenzae & $5(45.5)$ \\
Moraxella catarrhalis & $3(27.3)$ \\
Staphylococcus aureus & $2(18.2)$ \\
Rhinovirus & $2(18.2)$ \\
Pseudomonas aeruginosa & $1(9.1)$ \\
Negative cultures & $2(18.2)$ \\
\hline
\end{tabular}

a More than one microorganism was cultured in four patients

Horan et al. [11] which place an emphasis on identifying a progressive infiltrate in two consecutive chest radiographs in patients with underlying disease. However, in postoperative pediatric cardiac surgical patients it is very difficult to differentiate between infectious infiltrates and pulmonary over-circulation, fluid overload, atelectases and pleural effusion on chest radiographs. This indicates that the criteria proposed by Horan et al. [11] may not be fully applicable to pediatric patients after cardiac surgery. Other criteria include worsening gas exchange, reflected in a worsening $\mathrm{PaO}_{2} / \mathrm{FiO}_{2}$ ratio and/or an $\mathrm{A}-\mathrm{a}$ gradient which are already abnormal due to fluid overload, atelectases or intracardiac shunts in many patients after cardiac surgery. In our patients with VAP without shunting ( 8 of 11) the $\mathrm{PaO}_{2} / \mathrm{FiO}_{2}$ ratio decreased by an average of $16 \%$ (from 225 to $188 \mathrm{mmHg}$ ) and the $\mathrm{A}-\mathrm{a}$ gradient doubled on average from 120 to $249 \mathrm{mmHg}$. Further research is needed to address the issue of diagnosing VAP, especially in this specific patient group. We are currently performing a prospective review of the incidence of VAP.

The most common etiological agents in VAP in pediatric patients reported previously are $P$. aeruginosa and $S$. aureus $[2,16]$. We identified these bacterial species in 9.1 and $18.2 \%$, respectively. No methicillin-resistant $S$. aureus species were identified. The most commonly isolated organisms in our population were H. influenzae (45.5\%) and $M$. catarrhalis (27.3\%), probably representing nasopharyngeal flora as associated agents of VAP. All the cultured bacteria were sensitive to our empirical antibiotic regimen. Tan et al. [10] also reported gram-negative bacilli as the most frequent isolates $(86.1 \%)$, followed by fungi (7.6\%), and gram-positive cocci $(6.3 \%)$. The incidence of polymicrobial VAP was $36.4 \%$, similar to that reported by Srinivasan et al. [7]. No organisms were cultured from the samples from two patients $(18.2 \%)$, and rhinovirus was found by PCR in two patients $(18.2 \%)$, although it is unclear what role this played in the etiology of VAP. Of 11 patients with VAP, 9 had positive endotracheal cultures, obtained by standard endotracheal suction.

Of 76 endotracheal cultures that were taken, 44 were positive, and 31 patients had positive endotracheal cultures without any clinical signs or symptoms of pulmonary infection and were retrospectively classified as colonization. However, lower respiratory tract infections often begin with tracheal colonization that may progress to ventilator-associated tracheobronchitis (VAT), which can be diagnosed on the basis of clinical signs (fever, leukocytosis, purulent sputum), microbiological information (sputum cultures), and the absence of infiltrates on chest 
Table 3 Characteristics and outcomes of patients with and without VAP

\begin{tabular}{|c|c|c|c|}
\hline & $\begin{array}{l}\text { Patients with } \\
\text { VAP }(n=11)\end{array}$ & $\begin{array}{l}\text { Patients without } \\
\text { VAP }(n=114)\end{array}$ & $p$ value \\
\hline \multicolumn{4}{|l|}{ Baseline characteristics } \\
\hline Gender (male), $n(\%)$ & 7 (63.6) & $61(53.5)$ & 0.520 \\
\hline Age (months), mean \pm SD & $28.8 \pm 50.2$ & $15.4 \pm 26.3$ & 0.100 \\
\hline Weight $(\mathrm{kg})$, mean $\pm \mathrm{SD}$ & $11.6 \pm 12.4$ & $7.7 \pm 7.6$ & 0.140 \\
\hline PEISM III score $\geq 10, n(\%)$ & $7(63.5)$ & $31(27.2)$ & $0.033 *$ \\
\hline A genetic syndrome, $n(\%)$ & $2(18.2)$ & $16(14)$ & 0.66 \\
\hline Pulmonary hypertension, $n(\%)$ & $5(45.5)$ & $30(26.3)$ & 0.289 \\
\hline Previous operation, $n(\%)$ & $4(36.4)$ & $40(35.1)$ & 1.000 \\
\hline Prior antibiotics, $n(\%)$ & $1(9.1)$ & $3(2.6)$ & 0.310 \\
\hline \multicolumn{4}{|l|}{ Operation } \\
\hline RACHS score, mean \pm SD & $2.82 \pm 0.98$ & $2.87 \pm 0.96$ & 0.981 \\
\hline Use of cardiopulmonary bypass, $n(\%)$ & $11(100)$ & $91(80.5)$ & 0.191 \\
\hline Length of cardiopulmonary bypass (min), mean \pm SD & $155.3 \pm 65.2$ & $114.4 \pm 82.9$ & 0.145 \\
\hline Aortic cross-clamp time $(\mathrm{min})$, mean $\pm \mathrm{SD}$ & $90.9 \pm 62.5$ & $57.0 \pm 53.8$ & $0.056^{\mathrm{a}}$ \\
\hline Steroids, $n(\%)$ & $9(81.8)$ & $92(80.7)$ & 1.00 \\
\hline \multicolumn{4}{|l|}{ Ventilation, $n(\%)$} \\
\hline Cuffed endotracheal tube & $9(81.8)$ & $107(93.9)$ & 0.180 \\
\hline Steroids during ventilation & 0 & $2(1.8)$ & 1.00 \\
\hline \multicolumn{4}{|l|}{ Procedures, $n(\%)$} \\
\hline Delayed sternum closure & $0(0)$ & $21(18.4)$ & 0.209 \\
\hline Reoperation & $2(18.2)$ & $25(21.9)$ & 1.000 \\
\hline Transport out of the PICU & $3(27.3)$ & $14(12.3)$ & 0.168 \\
\hline \multicolumn{4}{|l|}{ Transfusion, $n(\%)$} \\
\hline Red blood cells & $9(81.8)$ & $98(86.0)$ & 0.659 \\
\hline Fresh frozen plasma & $7(63.6)$ & $37(32.5)$ & $0.050 *$ \\
\hline Platelets & $2(18.2)$ & $22(19.3)$ & 1.000 \\
\hline \multicolumn{4}{|l|}{ Nutrition, $n(\%)$} \\
\hline Total parenteral nutrition & $1(5.6)$ & $9(8.3)$ & 0.484 \\
\hline Nasojejunal tube & $3(27.3)$ & $13(11.4)$ & 0.149 \\
\hline \multicolumn{4}{|l|}{ Outcome } \\
\hline Duration of ventilation, mean $\pm \mathrm{SD}$ & $181.3 \pm 94.4$ & $118.1 \pm 138.3$ & $0.002 *$ \\
\hline Ventilation $\geq 72 \mathrm{~h}, n(\%)$ & $11(100)$ & $62(54.4)$ & $0.003 *$ \\
\hline PICU length of stay, mean \pm SD & $13.0 \pm 6.8$ & $10.4 \pm 10.2$ & $0.009 *$ \\
\hline Death, $n(\%)$ & $0(0)$ & $3(2.6)$ & 1.000 \\
\hline
\end{tabular}

$* p<0.05$

a Value approaching significance
Table 4 Logistic regression analysis of factors associated with VAP in PICU patients

\begin{tabular}{llll}
\hline & $\begin{array}{c}\text { Odds } \\
\text { ratio }\end{array}$ & $95 \%$ CI & $p$ value \\
\hline PRISM score $>10$ & 4.39 & $1.06-18.04$ & $0.041^{*}$ \\
Transfusion of fresh frozen plasma & 1.88 & $0.46-7.87$ & 0.390 \\
Aortic cross-clamp time (min) & 1.01 & $0.99-1.02$ & 0.132 \\
Age at admission (months) & 1.00 & $1.00-1.00$ & 0.376 \\
\hline
\end{tabular}

$* p<0.05$

radiographs. VAT can lead to VAP in some patients and treatment of VAT may be an important factor in preventing VAP [17]. In adult VAP it has also been shown that appropriate antimicrobial treatment of patients significantly improves outcome [4]. It is therefore important to obtain microbiological information. Protected specimen brush and bronchoalveolar lavage are recommended to avoid a high incidence of false-positive endotracheal cultures due to colonization [4] as they are a good alternative to bronchoalveolar lavage [18, 19].
The risk factors found in our study were different from those reported in general PICU populations (presence of a genetic syndrome, reintubation, enteral feeding, transport out of the PICU, duration of mechanical ventilation, and the presence of a central venous line) [3, 6-8]. In our study, patients with VAP were more likely to have an admission PRISM III score of $\geq 10(p=0.033)$ as confirmed by multivariate analysis. This could indicate patients who were more unstable during surgery or required more complex surgery, which is reinforced by the fact that they also had longer aortic cross-clamp times. Tang et al. [3] have reported previously that patients with complex congenital heart disease are more likely to develop VAP than patients with simple congenital heart disease. However, the complexity of cardiac surgery as defined by the RACHS-1 score did not correlate with development of VAP in our study (Table 1), a finding also reported by Fischer et al. [9]. Furthermore, none of our patients who developed VAP had delayed sternum closure compared to $18.4 \%$ among the other 114 patients (Table 3 ) and steroids were given before cardiopulmonary 
bypass to approximately $80 \%$ of patients in both groups $(p=1.00)$, and neither could therefore be identified as a risk factor for VAP. Only two patients received continued steroids because of low cardiac output syndrome, but neither developed VAP. However, steroids have been reported as a risk factor for VAP in the adult literature [20]. Furthermore, patients with VAP were more likely to have received a transfusion of fresh frozen plasma, although in multivariate analysis the difference was not statistically significant. Unfortunately, our numbers were too small to comment on the temporal relationship between fresh frozen plasma transfusion and the development of VAP. An increased risk of infections in patients treated with fresh frozen plasma has been reported previously in adult ICU patients [21].

The age of the patients with VAP was higher (mean 28.8 vs. 15.4 months), although this was not statistically significant. Further analysis did not identify a specific age group at risk. Colonization of the upper airway in the normal population changes with age, but whether this plays a role in the development of VAP needs to be further investigated. We maintain oral hygiene with oral swabs using water. Whether chlorhexidine mouthwash would lower the incidence of VAP is the subject of further investigation. Preventive interventions based on evidence in adult settings [22] have been shown to lead to a reduction in the incidence of VAP in pediatric patients [23, 24]. Patients with VAP had significantly prolonged mechanical ventilation and PICU length of stay. This has also been reported in previous studies $[6,8,9]$. There were no deaths in the group of patients with VAP. Only a few studies in pediatric patients have demonstrated a significantly higher mortality rate in patients with VAP $[3,25]$. Higher mortality due to VAP in adults is well documented [26].

The limitations of our study include the fact that it reflects a single-center experience, which may limit its generalizability. Due to the explorative character of this study, a formal power analysis was not performed. Because it was a retrospective study, the data collected could have been incomplete. However, all our data were prospectively gathered in our PDMS and were available for all patients. Possible misclassification was addressed by using very specific definitions. Therefore underestimation of our VAP rate, although possible, seems unlikely. However, the lack of a gold standard for the definition of VAP may limit the accuracy of the correlation with risk factors and outcomes. Despite these limitations the study has allowed us to establish a solid reference point for VAP in PICU patients in The Netherlands, and has provided us with valuable information for the setting up of future prospective studies.

\section{Conclusion}

VAP in pediatric patients following cardiothoracic surgery is a significant problem with longer duration of mechanical ventilation and longer PICU length of stay. Conventional criteria might not be fully applicable. The only independent risk factor was a PRISM score of $\geq 10$ on admission. Large prospective studies are needed to further evaluate the diagnostic criteria, risk factors and interventions which may reduce the incidence of VAP in this patient group.

Open Access This article is distributed under the terms of the Creative Commons Attribution Noncommercial License which permits any noncommercial use, distribution, and reproduction in any medium, provided the original author(s) and source are credited.

\section{References}

1. Elward AM (2003) Pediatric ventilatorassociated pneumonia. Pediatr Infect Dis J 22:445-446

2. National Nosocomial Infections Surveillance (NNIS) System (2001) National Nosocomial Infections Surveillance (NNIS) System Report, Data Summary from January 1992June 2001, issued August 2001. Am J Infect Control 29:404-421

3. Tang CW, Liu PY, Huang YF, Pan JY, Lee SS, Hsieh KS, Liu YC, Ger LP (2009) Ventilator-associated pneumonia after pediatric cardiac surgery in southern Taiwan. J Microbiol Immunol Infect 42:413-419
4. Chastre J, Fagon JY (2002) Ventilatorassociated pneumonia. Am J Respir Crit Care Med 165:867-903

5. Hortal J, Giannella M, Perez MJ, Barrio JM, Desco M, Bouza E, Munoz P (2009) Incidence and risk factors for ventilator-associated pneumonia after major heart surgery. Intensive Care Med 35:1518-1525

6. Elward AM, Warren DK, Fraser VJ (2002) Ventilator-associated pneumonia in pediatric intensive care unit patients: risk factors and outcomes. Pediatrics 109:758-764
7. Srinivasan R, Asselin J, Gildengorin G, Wiener-Kronish J, Flori HR (2009) A prospective study of ventilatorassociated pneumonia in children. Pediatrics 123:1108-1115

8. Almuneef M, Memish ZA, Balkhy HH, Alalem H, Abutaleb A (2004)

Ventilator-associated pneumonia in a pediatric intensive care unit in Saudi Arabia: a 30-month prospective surveillance. Infect Control Hosp Epidemiol 25:753-758

9. Fischer JE, Allen P, Fanconi S (2000) Delay of extubation in neonates and children after cardiac surgery: impact of ventilator-associated pneumonia. Intensive Care Med 26:942-949 
10. Tan L, Sun X, Zhu X, Zhang Z, Li J, Shu Q (2004) Epidemiology of nosocomial pneumonia in infants after cardiac surgery. Chest 125:410-417

11. Horan TC, Andrus M, Dudeck MA (2008) CDC/NHSN surveillance definition of health care-associated infection and criteria for specific types of infections in the acute care setting. Am J Infect Control 36:309-332

12. Jacobs JP, Jacobs ML, Lacour-Gayet FG, Jenkins KJ, Gauvreau K, Bacha E, Maruszewski B, Clarke DR,

Tchervenkov CI, Gaynor JW, Spray TL, Stellin G, O'Bien SM, Elliott MJ, Mavroudis C (2009) Stratification of complexity improves the utility and accuracy of outcomes analysis in a Multi-Institutional Congenital Heart Surgery Database: Application of the Risk Adjustment in Congenital Heart Surgery (RACHS-1) and Aristotle Systems in the Society of Thoracic Surgeons (STS) Congenital Heart Surgery Database. Pediatr Cardiol 30:1117-1130

13. Miller MA, Arndt JL, Konkle MA, Chenoweth CE, Iwashyna TJ, Flaherty KR, Hyzy RC (2011) A polyurethane cuffed endotracheal tube is associated with decreased rates of ventilatorassociated pneumonia. J Crit Care 26:280-286

14. Poelaert J, Depuydt P, De Wolf A, Van de Velde S, Herck I, Blot S (2008) Polyurethane cuffed endotracheal tubes to prevent early postoperative pneumonia after cardiac surgery: a pilot study. J Thorac Cardiovasc Surg 135:771-776
15. National Nosocomial Infections Surveillance (NNIS) System (2004) National Nosocomial Infections Surveillance (NNIS) System Report, data summary from January 1992 through June 2004, issued October 2004. Am J Infect Control 32:470-485

16. Raymond J, Aujard Y (2000) Nosocomial infections in pediatric patients: a European, multicenter prospective study. European study group. Infect Control Hosp Epidemiol 21:260-263

17. Craven DE, Chroneou A, Zias N, Hjalmarson KI (2009) Ventilatorassociated tracheobronchitis: the impact of targeted antibiotic therapy on patient outcomes. Chest 135:521-528

18. Mentec H, May-Michelangeli L, Rabbat A, Varon E, Le Turdu F, Bleichner G (2004) Blind and bronchoscopic sampling methods in suspected ventilator-associated pneumonia. A multicentre prospective study. Intensive Care Med 30:1319-1326

19. Sachdev A, Chugh K, Sethi M, Gupta D, Wattal C, Menon G (2010) Diagnosis of ventilator-associated pneumonia in children in resourcelimited setting: a comparative study of bronchoscopic and non-bronchoscopic methods. Pediatr Crit Care Med 11:258-266

20. Pawar M, Mehta Y, Khurana P, Chaudhary A, Kulkarni V, Trehan N (2003) Ventilator-associated pneumonia: incidence, risk factors, outcome, and microbiology. J Cardiothorac Vasc Anesth 17:22-28
21. Sarani B, Dunkman WJ, Dean L, Sonnad S, Rohrbach JI, Gracias VH (2008) Transfusion of fresh frozen plasma in critically ill surgical patients is associated with an increased risk of infection. Crit Care Med 36:1114-1118

22. Hawe CS, Ellis KS, Cairns CJ, Longmate A (2009) Reduction of ventilator-associated pneumonia: active versus passive guideline implementation. Intensive Care Med 35:1180-1186

23. Brilli RJ, Sparling KW, Lake MR, Butcher J, Myers SS, Clark MD, Helpling A, Stutler ME (2008) The business case for preventing ventilatorassociated pneumonia in pediatric intensive care unit patients. Jt Comm J Qual Patient Saf 34:629-638

24. Stokowski LA (2009) Preventing ventilator-associated pneumonia in infants and children.

http://www.medscape.org/viewarticle/ 709081

25. Bigham MT, Amato R, Bondurrant P, Fridriksson J, Krawczeski CD, Raake J, Ryckman S, Schwartz S, Shaw J, Wells D, Brilli RJ (2009) Ventilatorassociated pneumonia in the pediatric intensive care unit: characterizing the problem and implementing a sustainable solution. J Pediatr 154:582-587

26. Safdar N, Dezfulian C, Collard HR, Saint S (2005) Clinical and economic consequences of ventilator-associated pneumonia: a systematic review. Crit Care Med 33:2184-2193 